\title{
Mixed mode I/II stress intensity factors through the thickness of disc type specimens
}

\author{
Amr A. Abd-Elhady*
}

Mechanical Design Department, Faculty of Engineering, Helwan University, Cairo 11718, Egypt

\begin{tabular}{l}
\hline A R T I C L E I N F O \\
\hline Article history: \\
Received March 20, 2013 \\
Received in Revised form \\
September, 14, 2013 \\
Accepted 22 September 2013 \\
Available online \\
23 October 2013 \\
\hline Keywords: \\
Stress intensity factor \\
Mixed mode I/II \\
SCB specimen \\
CCCD specimen \\
Three dimensional finite element
\end{tabular}

\section{A B S T R A C T}

Mode I and mode II stress intensity factors (SIFs) through the thickness of edge crack in semi circular bend (SCB) and center cracked circular disc (CCCD) specimens have been analyzed using three dimensional finite element analysis. The effect of the CCCD and SCB specimen thickness on the through-thickness variations of SIFs has been studied. For all mode of mixity, the peak value of mode I SIF is found at mid plane of SCB specimen and for thin CCCD specimen, while, this location is shifted to be near the free surface plane in thick CCCD specimen. The variation of mode II SIF in CCCD and SCB specimens have a similar trend.

(c) 2013 Growing Science Ltd. All rights reserved.

\section{Introduction}

Cracks experience a combination of two major modes of loading: mode I and mode II due to arbitrary orientation of flaws relative to the overall applied loads. Two frequently employed disc type specimens are the center cracked circular disc (CCCD), subjected to diametral compression, often called the Brazilian disc, and the edge cracked semi circular bend (SCB) specimen subjected to threepoint bend loading. The major advantages in using these two specimens are that specimens can be easily extracted from the cores of rocks materials, they have a simple geometry and simple loading configuration. In addition, the test procedure is straightforward, there are few machining operations and different mode of mixities may be introduced from pure mode I to pure mode II. Hence these test specimens have been used frequently to investigate mixed mode crack growth of rock materials, concrete, biomaterials, and other material (e.g. Chen et al. 1998; Ouinas et al. 2009; Aliha \& Ayatollahi, 2009, 2013; Sallam \& Abd-Elhady, 2012; AL-Maghrabi \& Abd-Elhady, 2013; Aliha et al., 2010, 2012a,b; Saghafi et al., 2010). Ayatollahi and Aliha (2007) depicted that the normalized

* Corresponding author.

E-mail addresses: aa__elhady@yahoo.com (A. A. Abd-Elhady) 
mode I and mode II stress intensity factor are functions of the crack length ratio $a / R$ and crack angle $\beta$ only for CCCD specimen and crack length ratio $a / R$, crack angle $\beta$ and $S / R$ for SCB specimen as shown in Fig. 1.

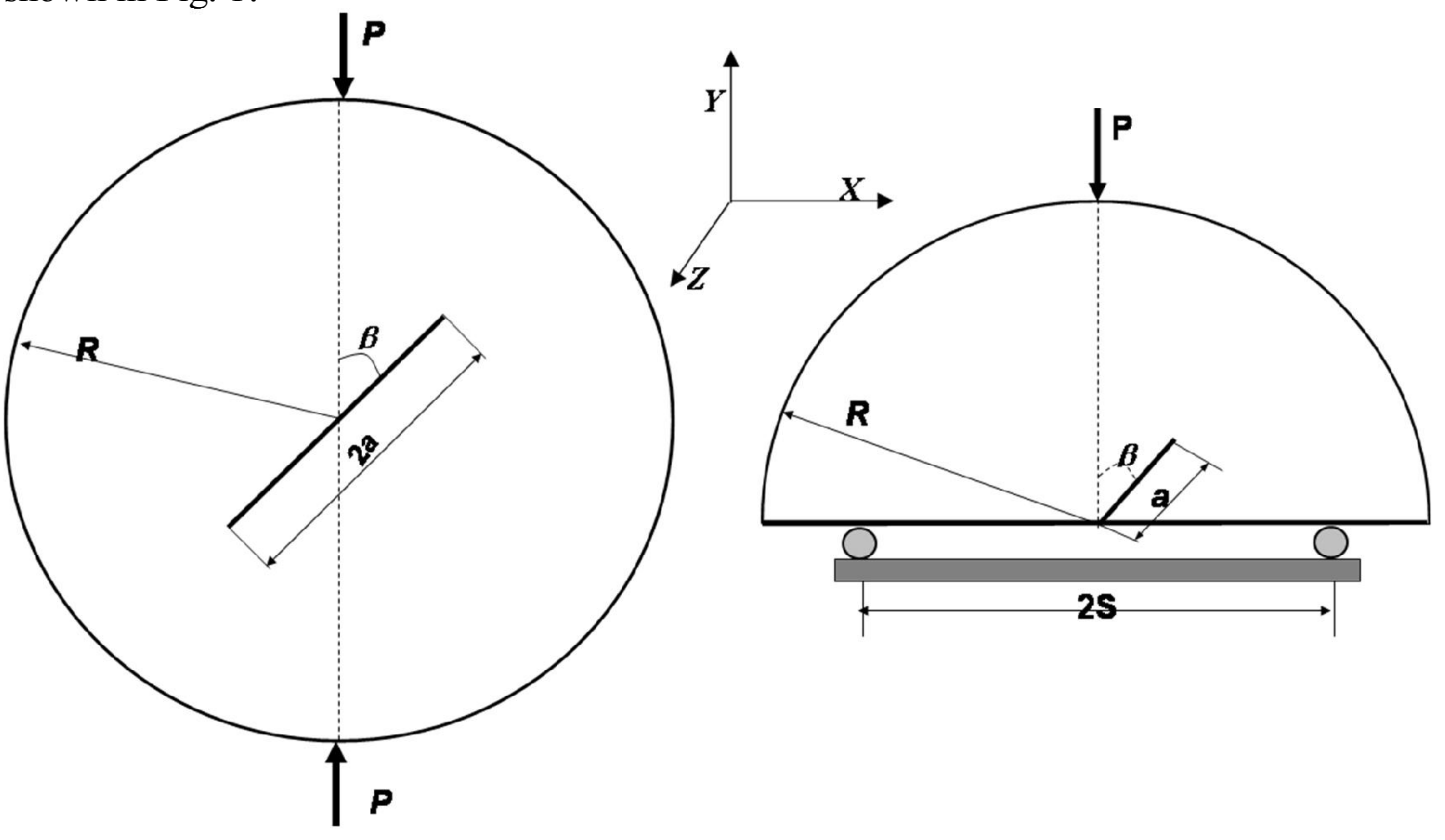

Fig. 1. Geometry and loading conditions of CCCD and SCB specimens subjected to mixed mode I/II loading

The stress state near an actual crack tip is always three-dimensional and can significantly influence crack growth. Hutar et al. (2010) show that, the stress singularity exponent is not constant along the crack front and the stress field around the crack tip are usually based on stress intensity factors. Garcia-Manrique et al. (2013) used Al 2024-T35 compact tension specimen under mode I nominal loading to evaluate the SIFs distribution along the thickness. They concluded that, a smaller SIFs value is present near the surface than in the interior causing a smaller plastic zone than the expected value with plane stress condition. Kwon and Sun (2000) concluded that, except for plates with very large thicknesses, the 2-D SIFs is quite different from the 3-D SIFs at the mid-plane. Furthermore, the profile of stress intensity along the thickness direction is still in question. Kown and Sun (2000) stated that, SIFs should drop to zero at the plate free surface due to the weaker singularity than square root, but this is difficult to obtain by the finite element method

Accurate stress analyses of these through-cracks components are needed for reliable prediction of their crack-growth and fracture strengths. However, because of the complexities of such problems, exact solutions are not available. To the best knowledge of the author, SIFs through the thickness of edge crack in SCB and CCCD specimens is still not fully studied. Among the very few research studies in this field, Aliha and Saghafi (2013) performed recently several three-dimensional numerical analyses to study the effect of thickness and Poisson's ratio on mixed mode fracture parameters of the SCB specimen. Therefore, this paper concentrated on computation the SIFs through the thickness of CCCD and of SCB specimens for different specimen thicknesses and mode of mixities using 3D FEA.

\section{Finite element analysis}

Fig. 1 shows the geometry and loading condition of the CCCD and SCB specimens used for mixed mode I/II fracture tests. In the CCCD specimen, the orientation of the center crack of length $2 a$ relative to the applied load $P$ is defined by the angle $\beta$ and varies the state of crack deformation, 
giving different combinations of modes I and II. Similarly for the SCB specimen, by changing the inclination angle $\beta$ of the edge crack of length $a$ with respect to the applied load $P$, various mode of mixities can be achieved. For both specimen shapes, $\beta=0^{\circ}$ corresponds to pure mode I (opening mode) loading. By increasing the loading angle $\beta$ from zero, mode II is introduced.

To study the effect of mode of mixity and the effect of specimen thickness, $B$, on through-thickness stress intensity factor, several CCCD and SCB specimens with different crack angles were simulated. The geometry and dimensions of the CCCD and SCB specimens are listed in Table 1. For the sake of comparison, the basic dimensions of CCCD and SCB specimens $R$ (specimen radius), $2 t$ or $B$ (specimen thickness), and $a$ were considered to be the same for each two corresponding specimen sizes (see Table 1). SCB specimen is placed on two bottom supports of distance $2 S$. Thus, the ratio of $a / R$ was equal to 0.3 and the ratio of $S / R$ was 0.43 in the SCB specimens. Mixity parameter, $M^{e}$, is defined as (Aliha et al., 2010):

$$
M^{e}=\frac{2}{\pi} \arctan \left(\frac{K_{I}}{K_{I I}}\right),
$$

where $K_{I}$ and $K_{I I}$ are mode I and mode II stress intensity factors, respectively. In the present analysis, the values of $M^{\mathrm{e}}$ varied through 1 (pure mode I), 0.75, 0.5, 0.25 and 0 for pure mode II.

The general-purpose finite element program ABAQUS (2002) was used. A three-dimensional finite element model has been developed to account for geometric and material behavior of isotropic material. In the present work, the domain integral method used to extract stress intensity factors (SIFs). The domain integral method has proven useful for both two and three-dimensional crack problems. In the domain integral method, a crack-tip contour integral is expressed as an equivalent domain/volume integral over a finite domain surrounding the crack tip. A domain integral method commonly used to extract stress intensity factors (SIFs) (Nakamura \& Parks, 1989; Nakamura, 1991; Gosz et al., 1998; Gosz \& Moran 2002). The finite element meshes constructed with hexagonal structural mesh, C3D8 (8-node linear brick) elements, are used under Standard/static analysis. Around from 32 planar layers are divided through the thickness of the specimen varying with the plate thickness. Within each layer, the size of element decreases gradually with distance from the crack tip decreasing. The finite element meshes in the neighborhood of the crack tip are much denser. The values of mode I and II stress intensity factor were traced over the crack front of the specimen from the mid plane of specimen where $z=0$ to the specimen surface where $z=t$. In the present analysis, the mode I and mode II normalized stress intensity factors are denoted as $Y_{I}$ and $Y_{I I}$, respectively, and it can be deduced from Lim et al. (1993) and Hutar et al. (2010). The general formula for normalized stress intensity factor $Y_{i}$, which is defined as:

$$
\begin{array}{lll}
Y_{i}=\frac{4 R t K_{i}}{P \sqrt{a \pi}} & i=I, I I & \text { for SCB specimen } \\
Y_{i}=\frac{2 R t K_{i}}{P} \sqrt{\frac{\pi}{a}} & i=I, I I & \text { for CCCD specimen }
\end{array}
$$

where:

$$
\begin{aligned}
& K_{I}=\text { mode I stress intensity factor } \\
& K_{I I}=\text { mode II stress intensity factor } \\
& t=B / 2 \text { half specimen thickness } \\
& P=\text { applied load } \\
& R=\text { radius of specimen } \\
& a=\text { crack length }
\end{aligned}
$$


The normalized mode $I$ and mode $I I$ stress intensity factors at the midpoint of the specimen (at $z=0$ ) are $Y_{\text {Imp }}$ and $Y_{\text {IImp }}$, respectively, and at surface point of specimen (at $\left.z=t\right)$ are $Y_{\text {Isurf }}$ and $Y_{\text {IIsurf }}$.

Table 1

Specimen geometries and crack inclination angles in the tested CCCD and SCB specimen

\begin{tabular}{ccccccccc}
\hline & $R(\mathrm{~mm})$ & $2 t(\mathrm{~mm})$ & $a(\mathrm{~mm})$ & \multicolumn{5}{c}{$\beta\left(^{\mathrm{o}}\right)$} \\
\cline { 5 - 9 } & $=B$ & & $M^{\mathrm{e}}=1$ & $M^{\mathrm{e}}=0.75$ & $M^{\mathrm{e}}=0.5$ & $M^{\mathrm{e}}=0.25$ & $M^{\mathrm{e}}=0$ \\
\hline \multirow{4}{*}{$\mathrm{CCCD}$} & 75 & 15 & 22.5 & 0 & 5 & 10.5 & 18 & 27 \\
& 75 & 30 & 22.5 & 0 & 5 & 10.5 & 18 & 27 \\
& 75 & 45 & 22.5 & 0 & 5 & 10.5 & 18 & 27 \\
& 75 & 60 & 22.5 & 0 & 5 & 10.5 & 18 & 27 \\
\hline \multirow{4}{*}{$\mathrm{SCB}$} & 75 & 15 & 22.5 & 0 & 18.5 & 33 & 42.5 & 50 \\
& 75 & 30 & 22.5 & 0 & 18.5 & 33 & 42.5 & 50 \\
& 75 & 45 & 22.5 & 0 & 18.5 & 33 & 42.5 & 50 \\
& 75 & 60 & 22.5 & 0 & 18.5 & 33 & 42.5 & 50 \\
\hline
\end{tabular}

\section{Results and discussion}

To verify the accuracy of the present result for SIFs evaluation, the values of various normalized mode I and mode II stress intensity factors at the surface of CCCD and SCB specimens $(Z=t)$, for $R$ $=75 \mathrm{~mm}, B=7.5 \mathrm{~mm}, a / R=0.3$ and $S / R=0.43$ are compared with the previous numerical results using 2-D analysis found in the literature, $R=50 \mathrm{~mm}, B=5 \mathrm{~mm}, a / R=0.3$ and $S / R=0.43$ (Ayatollahi \& Aliha 2007; Aliha et al., 2010), as shown in Figures 2 and 3. Figures 2 and 3 show a good agreement between the present results for normalized mode I and mode II stress intensity factors and those obtained by Ayatollahi and Aliha (2007,2008) and Aliha et al. 2010. The values of normalized mode I and mode II stress intensity factors at the mid plane (at $z=0)$ and at free surface $(z$ $=t$ ) of CCCD and SCB specimens are tabulated in tables 2 and 3 respectively. The value of $Y_{\text {Imp }}$ of CCCD specimen decreases by increasing $B / R$, while, $Y_{\text {Isurf }}$ increases. The value of $Y_{\text {Isurf }}$ of SCB decreases by increasing $B / R$. $Y_{\text {Isurf }}$ and $Y_{\text {Imp }}$ of CCCD and SCB specimens decrease by decreasing the value of mixity parameter.

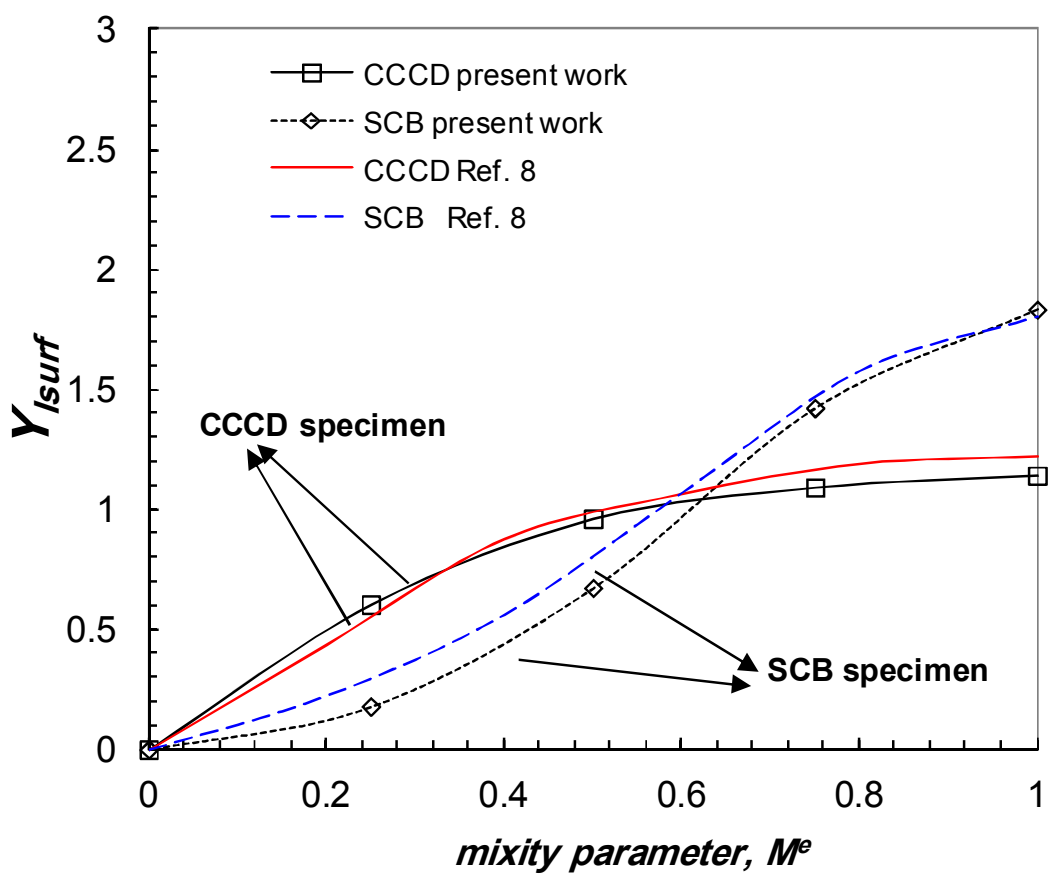

Fig. 2. Comparison between the present normalized $Y_{I}$ at the free surface of the specimen and those found in the literature using 2-D analysis (Aliha et al. 2010) 


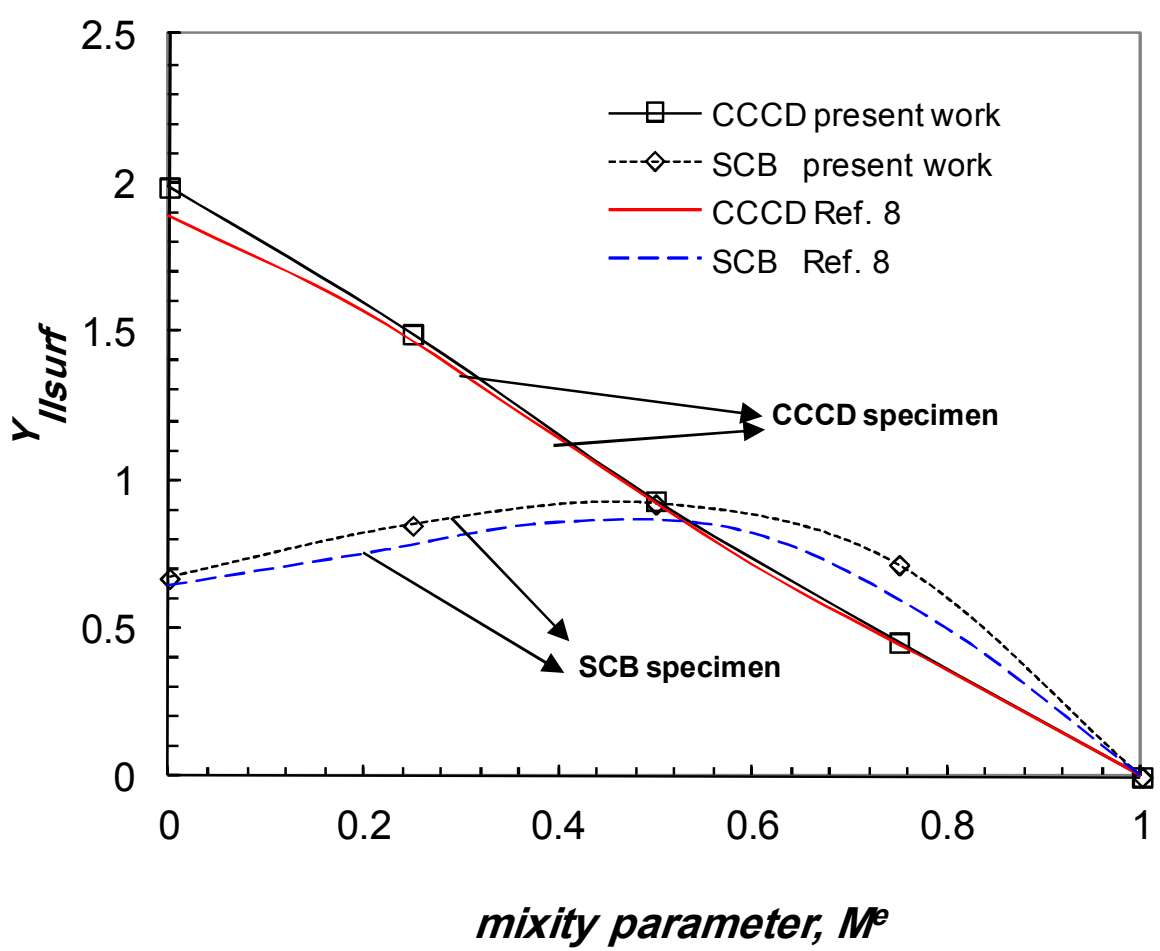

Fig. 3. Comparison between the present normalized $Y_{I I}$ at the free surface of the specimen and those found in the literature using 2-D analysis (Aliha et al. 2010)

Table 2

The values of normalized mode I stress intensity factor $Y_{\mathrm{I}}$ at mid point $(z / t=0)$ and at surface $(z / t=1)$ for the CCCD and SCB specimens for different values of $M^{\mathrm{e}}$ and different specimen thickness ratios.

\begin{tabular}{|c|c|c|c|c|c|c|c|}
\hline Specimen & $B / R$ & & $M^{\mathrm{e}}=1$ & $M^{\mathrm{e}}=0.75$ & $M^{\mathrm{e}}=0.5$ & $M^{\mathrm{e}}=0.25$ & $M^{\mathrm{e}}=0$ \\
\hline \multirow{8}{*}{ CCCD } & \multirow{2}{*}{0.2} & $Y_{\text {Imp }}$ & 1.17474 & 1.12806 & 0.97819 & 0.62394 & 0 \\
\hline & & $Y_{\text {Isur }}$ & 1.10662 & 1.05881 & 0.92223 & 0.58257 & 0 \\
\hline & \multirow{2}{*}{0.4} & $Y_{\text {Imp }}$ & 1.15584 & 1.10799 & 0.96398 & 0.60951 & 0 \\
\hline & & $Y_{\text {Isur }}$ & 1.12696 & 1.07748 & 0.93850 & 0.58931 & 0 \\
\hline & \multirow{2}{*}{0.6} & $Y_{\text {Imp }}$ & 1.13433 & 1.08638 & 0.95097 & 0.60126 & 0 \\
\hline & & $Y_{\text {Isur }}$ & 1.14119 & 1.09197 & 0.96065 & 0.60402 & 0 \\
\hline & \multirow{2}{*}{0.8} & $Y_{\text {Imp }}$ & 1.10684 & 1.06073 & 0.92154 & 0.57824 & 0 \\
\hline & & $Y_{\text {Isur }}$ & 1.18888 & 1.13710 & 0.99391 & 0.63199 & 0 \\
\hline \multirow{8}{*}{$\mathrm{SCB}$} & \multirow{2}{*}{0.2} & $Y_{\text {Imp }}$ & 2.09601 & 1.65985 & 0.85306 & 0.32454 & 0 \\
\hline & & $Y_{\text {Isur }}$ & 1.83337 & 1.42287 & 0.67280 & 0.17889 & 0 \\
\hline & \multirow{2}{*}{0.4} & $Y_{\text {Imp }}$ & 2.10187 & 1.67603 & 0.87104 & 0.35329 & 0 \\
\hline & & $Y_{\text {Isur }}$ & 1.77569 & 1.36208 & 0.60562 & 0.12369 & 0 \\
\hline & \multirow{2}{*}{0.6} & $Y_{\text {Imp }}$ & 2.10794 & 1.65012 & 0.86398 & 0.33354 & 0 \\
\hline & & $Y_{\text {Isur }}$ & 1.73930 & 1.29862 & 0.55021 & 0.07408 & 0 \\
\hline & \multirow{2}{*}{0.8} & $Y_{\text {Imp }}$ & 2.07458 & 1.64056 & 0.82505 & 0.31634 & 0 \\
\hline & & $Y_{\text {Isur }}$ & 1.71102 & 1.28638 & 0.51505 & 0.05856 & 0 \\
\hline
\end{tabular}


Table 3

The values of normalized mode II stress intensity factor $Y_{\text {II }}$ at mid point $(z / t=0)$ and at surface $(z / t=$ 1) for the CCCD and SCB specimens for different values of $M^{\mathfrak{e}}$ and different specimen thickness ratios

\begin{tabular}{|c|c|c|c|c|c|c|c|}
\hline Specimen & $B / R$ & & $M^{\mathrm{e}}=1$ & $M^{\mathrm{e}}=0.75$ & $M^{\mathrm{e}}=0.5$ & $M^{\mathrm{e}}=0.25$ & $M^{\mathrm{e}}=0$ \\
\hline \multirow{8}{*}{ CCCD } & \multirow{2}{*}{0.2} & $Y_{\text {IImp }}$ & 0 & 0.4295 & 0.8890 & 1.4035 & 1.8699 \\
\hline & & $Y_{\text {IIsur }}$ & 0 & 0.4470 & 0.9262 & 1.4643 & 1.9630 \\
\hline & \multirow{2}{*}{0.4} & $Y_{\text {IImp }}$ & 0 & 0.4304 & 0.8826 & 1.4140 & 1.8711 \\
\hline & & $Y_{\text {IIsur }}$ & 0 & 0.4463 & 0.9143 & 1.4656 & 1.9421 \\
\hline & \multirow{2}{*}{0.6} & $Y_{\text {IImp }}$ & 0 & 0.4268 & 0.8765 & 1.4049 & 1.8713 \\
\hline & & $Y_{\text {IIsur }}$ & 0 & 0.4529 & 0.9294 & 1.4916 & 1.9859 \\
\hline & \multirow{2}{*}{0.8} & $Y_{\text {IImp }}$ & 0 & 0.4250 & 0.8719 & 1.3979 & 1.8505 \\
\hline & & $Y_{\text {IIsur }}$ & 0 & 0.4511 & 0.9242 & 1.4807 & 1.9594 \\
\hline \multirow{8}{*}{ SCB } & \multirow{2}{*}{0.2} & $Y_{\text {IImp }}$ & 0 & 0.6592 & 0.8604 & 0.7937 & 0.6118 \\
\hline & & $Y_{\text {IIsur }}$ & 0 & 0.6865 & 0.9090 & 0.8299 & 0.6318 \\
\hline & \multirow{2}{*}{0.4} & $Y_{\text {IImp }}$ & 0 & 0.6676 & 0.8601 & 0.7753 & 0.6131 \\
\hline & & $Y_{\text {IIsur }}$ & 0 & 0.7012 & 0.9055 & 0.8150 & 0.6446 \\
\hline & \multirow{2}{*}{0.6} & $Y_{\text {IImp }}$ & 0 & 0.6728 & 0.8611 & 0.7889 & 0.6164 \\
\hline & & $Y_{\text {IIsur }}$ & 0 & 0.7139 & 0.9191 & 0.8470 & 0.6686 \\
\hline & \multirow{2}{*}{0.8} & $Y_{\text {IImp }}$ & 0 & 0.6527 & 0.8578 & 0.7796 & 0.6142 \\
\hline & & $Y_{\text {IIsur }}$ & 0 & 0.7051 & 0.9282 & 0.8502 & 0.6753 \\
\hline
\end{tabular}

Fig. 4 shows the variation of $Y_{I}$ normalized by $Y_{I m p}, Y_{I} / Y_{I m p}$, through the crack front of CCCD and SCB specimens for different $M^{e}$ and different $B / R$. For thin specimen, i.e. $B / R=0.2$, value of $Y_{I} / Y_{I m p}$ decreases gradually with increasing $z / t$ up to $z / t$ equals about 0.8 then the rate of decreasing change from gradually to sharply decrease for both specimens and all mode of mixities. For $B / R>0.2$ the distribution of $Y_{I} / Y_{\text {Imp }}$ is not the same for both specimens. In the case of CCCD specimen, the value of $Y_{I} / Y_{\text {Imp }}$ increases gradually to its peak value $Y_{\text {Imax }}$, then decreases sharply up to the specimen surface, i.e. bell shape. It is worth to note that, SIFs at the specimen surface should be equal zero, but it is difficult to get it by using FEM as mentioned by Kown and Sun (2000). The site of peak value of the $Y_{I} / Y_{\text {Imp }}$ is near the specimen surface. The peak value of $Y_{I} / Y_{\text {Imp }}$ of CCCD specimen increases by increasing $B / R$. This finding is in agreement with $\mathrm{Wu}(2006)$.

However, in the case of SCB specimen the shape of $Y_{I} / Y_{\text {Imp }}-\mathrm{z} / \mathrm{t}$ curve is not affected by B/R or mode of mixity, i.e. the peak value of $Y_{I} / Y_{\text {Imp }}$ is at the mid plane. This peak value of $Y_{I} / Y_{\text {Imp }}$ decreased by increasing $B / R$, i.e. opposite trend of $C C C D$ specimen with $\mathrm{B} / \mathrm{R}>0.2$. Therefore it can be concluded that, the shape of $Y_{I} / Y_{I m p}-\mathrm{z} / \mathrm{t}$ curve is similar for all mode of mixities and $\mathrm{B} / \mathrm{R}$ for SCB specimen and the peak value is found at the mid plane. In the case of CCCD specimen, the shape of $Y_{I} / Y_{I m p}-\mathrm{z} / \mathrm{t}$ curve depends on the specimen thickness. For thin specimen $(\mathrm{B} / \mathrm{R}=0.2)$, the shape is similar to that in $\mathrm{SCB}$ specimen, while, the bell shape is found for $\mathrm{B} / \mathrm{R}>0.2$ and the peak value is near the specimen surface. In these cases, the normalized mode I stress intensity factor is not only function of $a / R, \beta$ as concluded by Ayatollahi and Aliha (2008) but also function of $z / t$. 

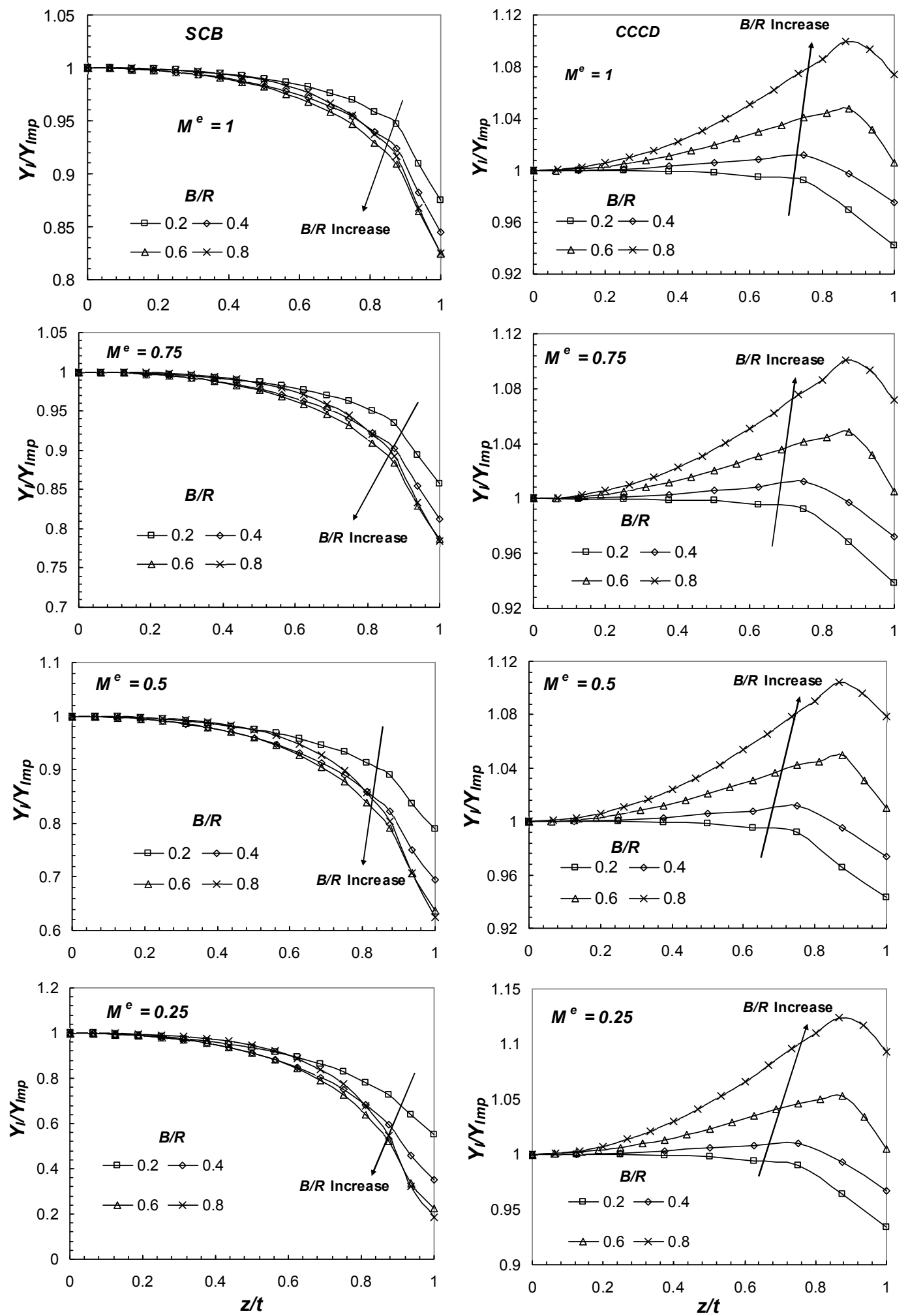

(a) SCB specimen

(b) CCCD specimen

Fig. 4. The through-thickness distributions of the normalized mode I stress intensity factor along crack front of (a) CCCD and (b) SCB specimens, for different $M^{e}$ 
Fig. 5 depicted the through-thickness variation of $Y_{I I} / Y_{\text {IImp }}$ along the crack front of CCCD and SCB specimens for different $M^{e}$ and $B / R$. The normalized mode II SIF through the crack front of SCB specimen has the similar trend from it exited in CCCD specimen as shown in the figure. For both specimens, the variation of $Y_{I I} / Y_{\text {IImp }}$ through the specimen thickness is small and not exceed $10 \%$. The maximum value of $Y_{I I}$ for both specimens located at the specimen surface.
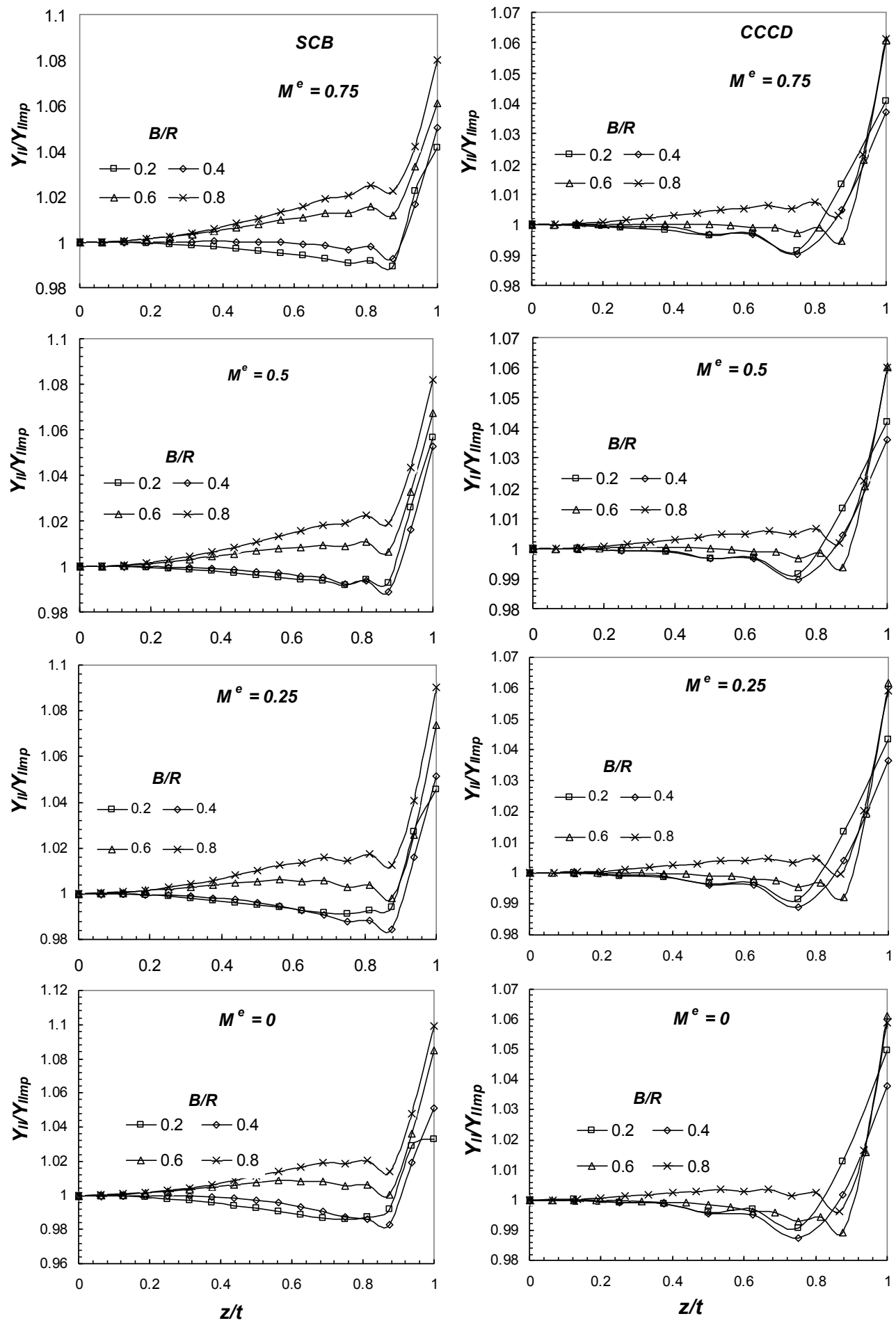

(a) SCB specimen

(b) CCCD specimen

Fig. 5. The through-thickness distributions of the normalized mode II stress intensity factor along crack front of (a) CCCD and (b) SCB specimens, for different $M^{e}$ 


\section{Conclusions}

The 3D FEA of mode I and mode II SIF through the crack front in SCB and CCCD specimens reveals the following conclusions:

1- The normalized mode I stress intensity factor $\left(Y_{I} / Y_{I m p}\right)$ is not only function of $a / R, \beta$ but also function of $z / t$.

2- The shape of $Y_{I} / Y_{I m p}-\mathrm{Z} / \mathrm{t}$ curve is similar for all mode of mixities and $\mathrm{B} / \mathrm{R}$ for SCB specimen and the peak value is found at the mid plane.

3- In the case of CCCD specimen, the shape of $Y_{I} / Y_{\text {Imp }}-\mathrm{z} / \mathrm{t}$ curve depends on the specimen thickness. For thin specimen $(B / R=0.2)$, the shape is similar to that in SCB specimen, while, the bell shape is found for $\mathrm{B} / \mathrm{R}>0.2$ and the peak value is near the specimen surface.

4- For both specimens, the maximum value of normalized mode II stress intensity factor located at the specimen surface.

\section{References}

ABAQUS user's manual version 6.9. (2002). Pawtucket, RI: Hibbitt. Karlsson and Sorensen Inc.

Aliha, M. R. M., \& Ayatollahi, M. R. (2009). Brittle fracture evaluation of a fine grain cement mortar in combined tensile-shear deformation. Fatigue \& Fracture of Engineering Materials \& Structures, 32(12), 987-994.

Aliha, M. R. M., \& Ayatollahi, M. R. (2013). Two-parameter fracture analysis of SCB rock specimen under mixed mode loading. Engineering Fracture Mechanics. 103, 115-123.

Aliha, M. R. M., \& Saghafi, H. (2013). The effects of thickness and Poisson's ratio on 3D mixedmode fracture. Engineering Fracture Mechanics. 98, 15-28.

Aliha, M. R. M., Ayatollahi, M. R., Smith, D. J., \& Pavier, M. J. (2010). Geometry and size effects on fracture trajectory in a limestone rock under mixed mode loading. Engineering Fracture Mechanics, 77(11), 2200-2212.

Aliha, M. R. M., Sistaninia, M., Smith, D. J., Pavier, M. J., \& Ayatollahi, M. R. (2012a). Geometry effects and statistical analysis of mode I fracture in guiting limestone. International Journal of Rock Mechanics and Mining Sciences, 51, 128-135.

Aliha, M. R. M., Ayatollahi, M. R., \& Akbardoost, J. (2012b). Typical Upper Bound-Lower Bound Mixed Mode Fracture Resistance Envelopes for Rock Material. Rock mechanics and rock engineering, 45(1), 65-74.

AL-Maghrabi, M. N. N., \& Abd-Elhady, A. A. (2013). Effective stress intensity factor of rock-like brittle materials subjected to different mode of mixity. Journal of American Science, 9(3), 216220.

Ayatollahi, M. R., \& Aliha, M. R. M. (2007). Wide range data for crack tip parameters in two disctype specimens under mixed mode loading. Computational materials science, 38(4), 660-670.

Ayatollahi, M. R., \& Aliha, M. R. M. (2008). On the use of Brazilian disc specimen for calculating mixed mode I-II fracture toughness of rock materials. Engineering Fracture Mechanics, 75(16), 4631-4641.

Chen, C. S., Pan, E., \& Amadei, B. (1998). Fracture mechanics analysis of cracked discs of anisotropic rock using the boundary element method. International Journal of Rock Mechanics and Mining Sciences, 35(2), 195-218.

Garcia-Manrique, J., Camas, D., Lopez-Crespo, P., \& Gonzalez-Herrera, A. (2013). Stress intensity factor analysis of through thickness effects. International Journal of Fatigue, 46, 58-66.

Gosz, M., Dolbow, J., \& Moran, B. (1998). Domain integral formulation for stress intensity factor computation along curved three-dimensional interface cracks. International Journal of Solids and Structures, 35(15), 1763-1783. 
Gosz, M., \& Moran, B. (2002). An interaction energy integral method for computation of mixedmode stress intensity factors along non-planar crack fronts in three dimensions. Engineering Fracture Mechanics, 69(3), 299-319.

Hutař, P., Náhlík, L., \& Knésl, Z. (2010). The effect of a free surface on fatigue crack behaviour. International Journal of Fatigue, 32(8), 1265-1269.

Kwon, S. W., \& Sun, C. T. (2000). Characteristics of three-dimensional stress fields in plates with a through-the-thickness crack. International journal of fracture, 104(3), 289-314.

Lim, I. L., Johnston, I. W., \& Choi, S. K. (1993). Stress intensity factors for semi-circular specimens under three-point bending. Engineering Fracture Mechanics, 44(3), 363-382.

Nakamura, T. (1991). Three-dimensional stress fields of elastic interface cracks. Journal of Applied Mechanics, 58, 939.

Nakamura, T., \& Parks, D. M. (1989). Antisymmetrical 3-D stress field near the crack front of a thin elastic plate. International Journal of Solids and Structures,25(12), 1411-1426.

Ouinas, D., Bouiadjra, B. B., Serier, B., Benderdouche, N., \& Ouinas, A. (2009). Numerical analysis of Brazilian bioceramic discs under diametrical compression loading. Computational Materials Science, 45(2), 443-448.

Saghafi, H., Ayatollahi, M. R., \& Sistaninia, M. (2010). A modified MTS criterion (MMTS) for mixed-mode fracture toughness assessment of brittle materials. Materials Science and Engineering: A, 527(21), 5624-5630.

Sallam, H. E. M., \& Abd-Elhady, A. A., (2012). Mixed Mode Crack Initiation and Growth in Notched Semi-Circular Specimens-Three Dimensional Finite Element Analysis. Asian Journal of Material Science, 4(2), 34-44.

$\mathrm{Wu}, \mathrm{Z}$. (2006). On the through-thickness crack with a curve front in center-cracked tension specimens. Engineering fracture mechanics, 73(17), 2600-2613. 